\title{
Prevalence, Risk Factors and Clinical Manifestation of Patients Suspected as having Obstructive Sleep Apnea in Songklanagarind Hospital Sleep Center
}

Krongthong Tawaranurak, M.D., Peesit Leelasawatsuk, M.D., Varaned Chaiyarukjirakun, M.Econ.

Department of Otolaryngology Head and Neck Surgery, Faculty of Medicine, Prince of Songkla University, Hat Yai, Songkhla 90110, Thailand.

Received 11 April 2019 • Revised 10 August 2019 • Accepted 10 August 2019 • Published online 30 September 2019

\section{Abstract:}

Objective: To identify the prevalence and to determine both risk factors and clinical manifestation of obstructive sleep apnea (OSA).

Material and Methods: A retrospective study was conducted to review the medical records and polysomnographic data of patients from March 2006 to December 2017.

Results: A total of 929 patients was enrolled, however, only 124 patients had habitual snoring (13.4\%). The prevalence of OSA and OSAS was $85.6 \%$ and $52.7 \%$ respectively. OSA was more prevalent in men than women (60.5\% vs $25.1 \%)$. The presence of HT or symptoms of choking, gasping and neurocognitive impairment were significantly greater in OSA patients compared with the non-OSA group. In multivariate analysis, it was revealed that male gender, age $\geq 50$ years, body-mass index $(\mathrm{BMI})>25 \mathrm{~kg} / \mathrm{m}^{2}$, neck circumference $(\mathrm{NC})>40 \mathrm{~cm}$ and waist to height ratio $(\mathrm{WHtR})>0.6$ were the significant predictors for OSA.

Conclusion: This study demonstrated that; OSA is a major health concern within the Thai population. Male gender, elderly age and those higher in BMI, NC or WHtR can be predicted as having the presence of OSA.

Keywords: obstructive sleep apnea, polysomnography, prevalence, risk factor

Contact: Asst. Prof. Krongthong Tawaranurak, M.D.

Department of Otolaryngology Head and Neck Surgery, Faculty of Medicine,

Prince of Songkla University, Hat Yai, Songkhla 90110, Thailand.

E-mail: wkroungt@medicine.psu.ac.th
J Health Sci Med Res 2019;37(4):305-312 doi: 10.31584/jhsmr.201965 www.jhsmr.org 


\section{Introduction}

Obstructive sleep apnea (OSA) is a common sleep disorder in the middle-aged population. It is characterized by a narrowing or complete collapse of the upper airway during sleep, leading to sleep fragmentation, excessive daytime sleepiness, mood changes and neurocognitive impairment. Furthermore, it interferes with the quality of life, and increases risks of motor vehicle accidents, work problem and cardiovascular morbidity and mortality. ${ }^{1-10}$ Subjects with OSA may complain of daytime sleepiness, choking or gasping during sleep, an unrefreshing sleep and morning headaches, while some patients may be asymptomatic. Nowadays, comprehensive sleep evaluations with various sleep questionnaires are used together for screening patients at risk. However, the standard diagnosis of OSA is still made by in-laboratory polysomnography.

Findings from most literatures have confirmed that those of a male gender, smokers, alcohol drinkers and hypertension were the significant risk factors of OSA. ${ }^{11,12}$ Besides this, other considered factors were neck circumference $(\mathrm{NC})>40 \mathrm{~cm}$, body mass index $(\mathrm{BMI})>30 \mathrm{~kg} / \mathrm{m}^{2}$, age $>50$ years of age. The history of excessive daytime sleepiness, using the Epworth sleepiness scale (ESS) score $\geq 11$, witnessed apnea, as well as which, choking also plays a role in the occurrence of OSA. ${ }^{13}$ However, these factors and their cut-off points might not be applicable in an Asian population, which had less obesity and differences in the craniofacial structure, compared with the Western population. ${ }^{14,15}$ In regards to the published prevalence in Asian populations, this was widely varying in range of 3.7 to $97.3 \%$, because of the variety in the criteria definition along with sleep study type used. ${ }^{16}$ Recently, in the Central Thai population, the prevalence of OSA was $11.4 \%$, while that of obstructive sleep apnea syndrome was $4.4 \%$. The prevalence of OSA was $15.4 \%$ and $6.3 \%$ in men and women, respectively. ${ }^{17}$ The aim of this present study is to identify the prevalence, and to determine the risk factors and clinical manifestation of OSA.

\section{Material and Methods}

\section{Study population}

All patients presenting with snoring, or other symptoms with suspected OSA who underwent polysomnography from March 2006 to December 2017 at Songklanagarind Hospital's sleep center, a tertiary hospital in southern Thailand, were included. For every patient, the data was recorded; including age, body mass index, gender, symptoms associated with OSA, Epworth sleepiness scale score (ESS), Friedman tongue position (FTP) ${ }^{18}$, NC, waist circumference (WC) and polysomnographic findings. NC was measured at the cricoid level, and WC was measured at the umbilical level, at the end of expiration, while patients were standing. Patients with incomplete data were excluded from the study. Type I polysomnography studies were conducted at the sleep center. The study consisted of electroencephalography (EEG), electrooculography, chin and leg electromyography, electrocardiography, thermistors and nasal pressure transducer for oronasal airflow, thoracic and abdominal belts for respiratory efforts, pulse oximetry for oxyhemoglobin level, tracheal microphone for snoring and sensors for sleeping position. The data recordings were scored manually by use of standard criteria. ${ }^{19}$ The EEG was scored into the five stages of sleep, including stage wakefulness (W), stage non-rapid eye movement1 (N1), stage N2, stage $\mathrm{N} 3$, and stage rapid eye movement (REM). ${ }^{19}$ Apnea was scored when there was a drop in the thermistor signal by $\geq 90.0 \%$, of the pre-event baseline, for $\geq 10$ seconds. The definition of hypopnea used either a $30.0 \%$ or $50.0 \%$ drop in nasal pressure signals for 10 seconds, or greater, which was associated with $\geq 3.0 \%$ desaturation, or an arousal. ${ }^{19}$ The apnea hypopnea index $(\mathrm{AHI})$ was calculated by the number of apneas and hypopneas, per 
hour, of total sleep time. Excessive daytime sleepiness (EDS) was self-assessed by using ESS questionnaires. ${ }^{20,21}$ A score of $>10$ was considered to be suggestive of EDS. OSA, this was defined as: an AHI score of $>5$. Obstructive sleep apnea syndrome (OSAS) was defined as: an $\mathrm{AHI}$ score of $>5$, with the presence of EDS. ${ }^{22}$ The OSA severity was defined as: mild for $\mathrm{AHI} \geq 5$ and $<15$, moderate for $\mathrm{AHI} \geq 15$ and $\leq 30$ and severe for $\mathrm{AHI}>30 .^{22}$ This retrospective study was approved by the Ethics Committee of the Faculty of Medicine, Prince of Songkla University. And, this article did not contain any studies with human participants performed by any of the authors.

\section{Statistical methods}

The prevalence was reported in percentage of proportion. Numerical data were described using mean and standard deviation (S.D.) or median and interquartile range (IQR) based on their distribution. Comparison between groups was performed with unpaired t-test for continuous variables, and chi-square test for nominal variables. Wilcoxon Mann Whitney test was used to compare ESS. The correlation was tested by Spearman correlation coefficients. Odd ratios (ORs) and 95\% confidence intervals (Cls) were determined. Logistic regression was used to analyze the significant factors in relation to OSA. All statistical analysis was performed using Epidata software (version 3.1) and R software (version 3.4.2) A p-value of less than 0.05 was considered to be statistically significant.

\section{Results}

\section{Prevalence of obstructive sleep apnea}

A total of 929 patients, undergoing in-laboratory polysomnography, were enrolled in this study. Among these patients, 795 patients had OSA (85.6\%), 490 patients had OSAS (52.7\%) and 124 patients had habitual snoring (13.4\%). The prevalence of OSA was $60.5 \%$ and $25.1 \%$ in men and women, respectively. The percentage of mild, moderate and severe OSA was $23.1 \%, 18.0 \%$ and $44.5 \%$, respectively.

Ages ranged from 18 to 85 years, with a male predominance of 622 patients $(67.0 \%)$. The male-to-female ratio was significant increasingly in the OSA group as 2.4:1. The mean BMI was higher in the OSA group, than in the non-OSA group $\left(30.2 \pm 8.5 \mathrm{~kg} / \mathrm{m}^{2}\right.$ vs $25.7 \pm 4.8$ $\mathrm{kg} / \mathrm{m}^{2} ; \mathrm{p}$-value $\left.<0.001\right)$. The characteristics of age, sex, $\mathrm{BMI}, \mathrm{NC}, \mathrm{WC}$ and waist-to-height ratio (WHtR) were statistically significant different in both groups. The presence of HT was greater in OSA subjects. In the OSA group, 461 patients (58.0\%) had a FTP III-IV, and a larger tonsil grading was shown more in this group. The demographic data along with risk factors of OSA and the non-OSA group are summarized in Table 1.

\section{Clinical manifestation and PSG findings}

In OSA patients, only 5 patients had no snoring (0.6\%). The OSA group seemed to have higher ESS scores coupled with excessive daytime sleepiness. Also, the presence of choking, gasping and neurocognitive impairment symptoms were significantly greater in OSA patients, compared with non-OSA, as shown in Table 1. Furthermore, the symptoms of recurrent awakening during the night, and vehicle accidents were found more common in the moderate to severe OSA group. The polysomnographic data is shown in Table 2. In the OSA group, there was a significant increasing in stage $\mathrm{N} 1$ and a reduction in stage REM of sleep. The lowest oxygen saturation was lower and the oxygen desaturation index was higher in OSA patients.

\section{Risk factors associated with OSA}

The results of univariate analysis are shown in Table 3. Male gender, age $\geq 50$ years, BMl $>25 \mathrm{~kg} / \mathrm{m}^{2}$, 
$\mathrm{NC}>40 \mathrm{~cm}, \mathrm{WC}>101 \mathrm{~cm}, \mathrm{WHtR}>0.6$, ESS score $>10$ and FTP III-IV showed significant correlation with an $\mathrm{AHI}$ score of $\geq 5$. The presence of HT, and the symptoms of choking, gasping as well as neurocognitive impairment were associated with OSA. Stepwise multivariate analysis identified that male gender, age $\geq 50$ years, $\mathrm{BMI}>25$ $\mathrm{kg} / \mathrm{m}^{2}, \mathrm{NC}>40 \mathrm{~cm}$ and $\mathrm{WHtR}>0.6$ were the significant predictors for OSA. Furthermore, the $\mathrm{NC}>40 \mathrm{~cm}$ was the most important predictor for severe OSA, with an odds ratio of $4.62[95 \%$ confidence interval $(\mathrm{Cl}) 3.38-6.32$, p-value $<0.001]$.

Table 1 Demographic characteristics of the study population $(n=929)$

\begin{tabular}{|c|c|c|c|}
\hline Characteristics & $\begin{array}{l}\text { Non-OSA subjects } \\
(n=134)\end{array}$ & $\begin{array}{l}\text { OSA subjects } \\
(n=795)\end{array}$ & p-value \\
\hline Age (year) & & & 0.005 \\
\hline$<50$ & $77(57.5)$ & $350(44.0)$ & \\
\hline$\geq 50$ & $57(42.5)$ & $445(56.0)$ & \\
\hline Gender & & & $<0.001$ \\
\hline Male & $60(44.8)$ & $562(70.7)$ & \\
\hline Female & $74(55.2)$ & $233(29.3)$ & \\
\hline $\mathrm{BMI}^{\dagger}\left(\mathrm{kg} / \mathrm{m}^{2}\right)$ & $25.7(4.8)$ & $30.2(8.5)$ & $<0.001$ \\
\hline Neck circumference ${ }^{\dagger}(\mathrm{cm})$ & $35.3(3.7)$ & $39.0(4.3)$ & $<0.001$ \\
\hline Waist circumference ${ }^{\dagger}(\mathrm{cm})$ & $89.0(12.3)$ & $100.3(16.0)$ & $<0.001$ \\
\hline $\mathrm{WHtR}^{\dagger}$ & $0.5(0.1)$ & $0.6(0.1)$ & $<0.001$ \\
\hline FTP III-IV & $72(53.7)$ & $461(58.0)$ & 0.002 \\
\hline Tonsils grade $3-4$ & $5(3.7)$ & $71(8.9)$ & 0.020 \\
\hline Retrognathia & $25(18.7)$ & $137(17.2)$ & 0.250 \\
\hline Habitual smoking & $1(0.7)$ & $14(1.8)$ & 0.202 \\
\hline Habitual drinking & $10(7.5)$ & $80(10.1)$ & 0.464 \\
\hline Hypertension & $20(14.9)$ & $248(31.2)$ & $<0.001$ \\
\hline ESS score $^{\dagger}$ & $8.9(3.9)$ & $9.8(4.5)$ & 0.044 \\
\hline Excessive daytime sleepiness & $38(28.8)$ & $293(37.7)$ & 0.063 \\
\hline Habitual snoring & $124(13.4)$ & $734(79.0)$ & 0.135 \\
\hline Choking or gasping & $56(6.0)$ & $357(38.4)$ & 0.040 \\
\hline Recurrent awakening & $28(3.0)$ & $170(18.3)$ & 0.857 \\
\hline Morning headache & $20(2.2)$ & $151(16.3)$ & 0.090 \\
\hline Unrefreshing sleep & $56(6.0)$ & $280(30.1)$ & 0.333 \\
\hline Neurocognitive impairment & $44(4.7)$ & $183(19.7)$ & 0.017 \\
\hline Accident or near miss accident & $7(5.2)$ & $45(5.7)$ & 1.000 \\
\hline
\end{tabular}

OSA=obstructive sleep apnea, $\mathrm{WH} R \mathrm{tR}=$ waist to height ratio, FTP=Friedman tongue position, ESS=Epworth sleepiness scale, ${ }^{\dagger}$ mean $(\mathrm{S} . \mathrm{D}$. 
Table 2 The polysomnographic measures of the study population $(n=929)$

\begin{tabular}{|c|c|c|c|}
\hline Parameters & $\begin{array}{l}\text { Non-OSA subjects } \\
(n=134)\end{array}$ & $\begin{array}{l}\text { OSA subjects } \\
(n=795)\end{array}$ & p-value \\
\hline Sleep latency ${ }^{\dagger}$ (min) & $13.3(14.9)$ & $13.3(15.9)$ & 0.996 \\
\hline REM latency $^{\dagger}(\min )$ & $132.9(77.7)$ & $120.7(65.5)$ & 0.060 \\
\hline Stage $\mathrm{N}^{\dagger}(\%)$ & $17.7(11.2)$ & $27.6(18.9)$ & $<0.001$ \\
\hline Stage $\mathrm{N}^{\dagger}(\%)$ & $54.4(11.1)$ & $51.5(14.6)$ & 0.030 \\
\hline Stage $\mathrm{N}^{\dagger}(\%)$ & $11.9(11.2)$ & $10.2(11.5)$ & 0.096 \\
\hline Stage $\operatorname{REM}^{\dagger}(\%)$ & $16.0(6.9)$ & $11.0(8.3)$ & $<0.001$ \\
\hline Minimum oxygen saturation ${ }^{\dagger}(\%)$ & $89.1(4.6)$ & $78.2(10.3)$ & $<0.001$ \\
\hline Oxygen desaturation index ${ }^{\dagger}$ (events/hrs) & $1.5(1.3)$ & $34.5(31.0)$ & $<0.001$ \\
\hline
\end{tabular}

REM=rapid eye movement, N1=non rapid eye movement1, N2=non rapid eye movement2, N3=non rapid eye movement3,

OSA=obstructive sleep apnea

Table 3 Risk factors associated with obstructive sleep apnea

\begin{tabular}{|c|c|c|}
\hline Characteristics & $\begin{array}{l}\text { Univariate analysis } \\
\text { odd ratio }(95 \% \mathrm{CI})\end{array}$ & $\begin{array}{l}\text { Stepwise multivariate analysis } \\
\text { Adjusted odd ratio ( } 95 \% \mathrm{Cl})\end{array}$ \\
\hline Male gender & $2.97(2.05-4.32)$ & $3.93(2.52-6.12)$ \\
\hline Age $\geq 50$ & $1.71(1.19-2.49)$ & $2.55(1.66-3.91)$ \\
\hline $\mathrm{BMI}>25 \mathrm{~kg} / \mathrm{m}^{2}$ & $3.43(2.35-4.99)$ & $1.72(1.07-2.77)$ \\
\hline $\mathrm{NC}>40 \mathrm{~cm}$ & $6.31(3.16-12.61)$ & $3.01(1.35-6.70)$ \\
\hline$W C>101 \mathrm{~cm}$ & $4.10(2.38-7.06)$ & \\
\hline WHtR $>0.6$ & $3.19(2.01-5.05)$ & $2.59(1.43-4.69)$ \\
\hline ESS score $>10$ & $1.49(1.00-2.24)$ & \\
\hline FTP III-IV & $1.66(1.11-2.48)$ & \\
\hline $\mathrm{HT}$ & $2.58(1.57-4.25)$ & \\
\hline Choking or gasping & $1.62(1.02-2.55)$ & \\
\hline Neurocognitive impairment & $0.86(0.48-1.52)$ & \\
\hline
\end{tabular}

$\mathrm{BMl}=$ body mass index, $\mathrm{NC}=$ neck circumference, $\mathrm{WC}=$ waist circumference, $\mathrm{WH}$ tR=waist to height ratio, $\mathrm{FTP}=\mathrm{Friedman}$ tongue position, ESS=Epworth sleepiness scale, $\mathrm{HT}=$ hypertension, $\mathrm{Cl}=$ confidence interval

\section{Discussion}

The present study represents the high-risk population, based on the survey of OSA in a tertiary care hospital in southern Thailand. We found that the burden of disease was quite high. The prevalence of OSA and OSAS in this study was $85.6 \%$ and $52.7 \%$, respectively. In the past, Young and colleagues ${ }^{2}$ reported the prevalence of OSA in middle-aged men and women as $24.0 \%$ and $9.0 \%$, respectively. ${ }^{2}$ Moreover, the published prevalence in the Asian population is widely varying in range from 3.7 to $97.3 \%$, due to the difference in the criteria definition, and sleep study type used. $^{16}$ One study, conducted with the central Thai population, reported the prevalence of OSA as: $11.4 \%$, and that of OSAS as: $4.4 \% .^{17}$ Moreover, the 
prevalence was higher in high-risk populations, such as morbid obesity undergoing bariatric surgery, and was estimated to be $77.0-88.0 \% .{ }^{23,24}$ Musman and colleagues ${ }^{25}$, studied patients, who submitted for polysomnography, and reported the prevalence of sleep apnea as $71.2 \%$. In this study, the majority of patients were referred for a sleep study when the presence of highly suspicion sleep apnea was indicated, including morbid obese patients.

The clinical symptoms alone were quite difficult to obtain the definite diagnosis, because of the non-specificity of symptoms as well as the lacking of patient's awareness. Although the OSA screening questionnaires were widely popular, the excessive daytime sleepiness, evaluated by ESS score, might not be used alone in OSA screening because the sleepiness could present in a normal population. This may simply be caused by sleep deprivation, medical effects or psychiatric conditions. Additionally, the STOP-Bang questionnaire was another popular screening tool for identifying OSA in surgical patients. A score of 3 out of 8 , had been considered highly sensitive for detecting OSA. However, its specificity was reported to be as low as $36.0 \%$, resulting in a high false-positive rate. ${ }^{26}$ Moreover, its BMI cut-off point was not applicable for an Asian population, whereas in this study the author focused on a more suitable BMI cut-off point for Thai people. Additionally, the symptoms of choking, gasping or neurocognitive impairment might be used to co-evaluate patients suspected for OSA. However, a sleep study was still needed, so as to make a standard diagnosis of OSA for these patients.

Male gender was the strongest risk factor of having OSA. The previous studies have shown that men have a higher rate of OSA, than those of women, varying as $9.0-52.1 \%$, in regards to the differences in upper airway shape and genioglossal muscle activity during the awake state, craniofacial morphology, and pattern of fat deposition. ${ }^{1-3,16,17}$ In this study, the male-to-female ratio was 2.4:1, relevant to previous studies, which reported approximately
$2: 1$ to $3: 1 .^{1,3}$ An elderly age was also another risk for OSA. The prevalence of OSA in the population aged 50-70 years, was strikingly high, and was estimated to be at: $43.2 \%$ in men and $27.8 \%$ in women. ${ }^{27}$ This study also found that the prevalence of OSA in $\geq 50$ years of age was higher $(47.9 \%)$ than the age $<50$ years $(37.7 \%)$, and had approximately a 2.5-fold risk for developing OSA. Obesity was an important risk factor for OSA in Western populations with several studies having demonstrated an increase in the prevalence of OSA being correlated with increasing $\mathrm{BMI}^{27} \mathrm{WHtR}$ was the another anthropometric index. It was widely used as the assessment of obesity, as an early health warning measurement, which is associated with cardio-metabolic risk. ${ }^{28,29} \mathrm{NC}$, a marker of upper body adipose tissue distribution, has recently been published from many studies as an important measure to detect patients at risk of OSA, as it was much easier to measure in routine clinical practice, than waist circumference. $^{30,31}$ Moreover, the measurement of waist and hip circumferences was quite difficult in patients with severe obesity, whom had excessive fat at the abdominal wall. As the World Health Organization's recommendation of using the lower BMI cut-off point in an Asian population ${ }^{32}$, we confirmed that the measures of body habitus including $\mathrm{BMI}>25 \mathrm{mg} / \mathrm{m}^{2}, \mathrm{NC}>40 \mathrm{~cm}, \mathrm{WHtR}>0.6$ as being the significant predictors of OSA in our study.

The strength of this study was that our sample size was very large and it was performed in a universitybased hospital where demographic data, clinical features and standard in-laboratory polysomnographic data were available for all patients. Additionally, we used the gold standard test, overnight in-laboratory polysomnography study, for determination of OSA. A potential weakness of the present study was referral bias resulting from the high risk population not being a representative of the community. 


\section{Conclusion}

In conclusion, this study demonstrated that: OSA is one of the major health concerns for the adult, Thai population. The risk factors, which significantly predicted the presence of OSA, included male gender, age $>50$ years, and obesity assessed by BMl of $>25 \mathrm{~kg} / \mathrm{m}^{2}$, NC $>40 \mathrm{~cm}$ or $\mathrm{WHtR}>0.6$.

\section{Acknowledgement}

The authors would like to thank the Faculty of Medicine, Prince of Songkla University for funding and Nannapat Pruphetkaew for data analysis.

\section{Conflict of interest}

The authors declare that there are no conflict of interest regarding the publication of this paper.

\section{References}

1. Jennum P, Riha RL. Epidemiology of sleep apnoeahyponoea syndrome and sleep-disordered breathing. Eur Respir $J$ 2009;33:907-14.

2. Young T, Palta M, Dempsey J, Skatrud J, Weber S, Badr S. The occurrence of sleep-disordered breathing among middle-aged adults. N Engl J Med 1993;328:1230-5.

3. Young T, Peppard PE, Gottlieb DJ. Epidemiology of obstructive sleep apnea: a population health perspective. Am J Respir Crit Care Med 2002;165:1217-39.

4. George CF. Sleep apnea, alertness, and motor vehicle crashes. Am J Respir Crit Care Med 2007;176:954-6.

5. Peppard PE, Young T, Palta M, Skatrud J. Prospective study of the association between sleep-disordered breathing and hypertension. N Engl J Med 2000;342:1378-84.

6. Nieto FJ, Young TB, Lind BK, Shahar E, Samet JM, Redline $S$, et al. Association of sleep-disordered breathing, sleep apnea, and hypertension in a large community-based study. Sleep Heart Health Study. JAMA 2000;283:1829-36.

7. Ip MS, Lam B, Ng MM, Lam WK, Tsang KW, Lam KS. Obstructive sleep apnea is independently associated with insulin resistance. Am J Respir Crit Care Med 2002;165: 670-6.

8. Redline S, Yenokyan G, Gottlieb DJ, Shahar E, O'Connor GT, Resnick HE, et al. Obstructive sleep apnea-hypopnea and incident stroke: the sleep heart health study. Am J Respir Crit Care Med 2010;182:269-77.

9. Marshall NS, Wong KK, Liu PY, Cullen SR, Knuiman MW, Grunstein RR. Sleep apnea as an independent risk factor for all-cause mortality: the Busselton Health Study. Sleep 2008;31:1079-85.

10. Young T, Finn L, Peppard PE, Szklo-Coxe M, Austin D, Nieto FJ, et al. Sleep disordered breathing and mortality: eighteenyear follow-up of the Wisconsin sleep cohort. Sleep 2008;31: 1071-8.

11. Young T, Shahar E, Nieto FJ, Redline S, Newman AB, Gottlieb DJ, et al. Predictors of sleep-disordered breathing in community-dwelling adults: the Sleep Heart Health Study. Arch Intern Med 2002;162:893-900.

12. Young T, Skatrud J, Peppard PE. Risk factors for obstructive sleep apnea in adults. JAMA 2004;291:2013-6.

13. Ibrahim AS, Almohammed AA, Allangawi MH, A Sattar HA, Mobayed HS, Pannerselvam B, et al. Predictors of obstructive sleep apnea in snorers. Ann Saudi Med 2007;27:421-6.

14. Lee RW, Vasudavan S, Hui DS, Prvan T, Petocz P, Darendeliler MA, et al. Differences in craniofacial structures and obesity in Caucasian and Chinese patients with obstructive sleep apnea. Sleep 2010;33:1075-80.

15. Li KK, Kushida C, Powell NB, Riley RW, Guilleminault C. Obstructive sleep apnea syndrome: a comparison between far-east Asian and white men. Laryngoscope 2000;110: 1689-93.

16. Mirrakhimov AE, Sooronbaev T, Mirrakhimov EM. Prevalence of obstructive sleep apnea in Asian adults: a systematic review of the literature. BMC Pulm Med 2013;13:10.

17. Neruntarat C, Chantapant S. Prevalence of sleep apnea in $\mathrm{HRH}$ Princess Maha Chakri Sirindhorn Medical Center, Thailand. Sleep Breath 2011;15:641-8.

18. Friedman M, Hamilton C, Samuelson CG, Lundgren ME, Pott $T$. Diagnostic value of the Friedman tongue position and Mallampati classification for obstructive sleep apnea: a meta-analysis. Otolaryngol Head Neck Surg 2013;148: 540-7.

19. Berry RB, Brooks R, Gamaldo CE, Harding SM, Lloyd RM, 
Quan SF, et al. The AASM manual for the scoring of sleep and associated events: rules, terminology and technical specifications, version 2.4. Darien, IL: American Academy of Sleep Medicine; 2017.

20. Banhiran W, Assanasen P, Nopmaneejumruslers C, Metheetrairut C. Epworth sleepiness scale disordered breathing: the reliability and validity of the Thai version. Sleep Breath 2011; 15:571-7.

21. Johns MW. A new method for measuring daytime sleepiness: the Epworth sleepiness scale. Sleep 1991;14:540-5.

22. Kapur VK, Auckley DH, Chowdhuri S, Kuhlmann DC, Mehra R, Ramar K, et al. Clinical practice guideline for diagnostic testing for adult obstructive sleep apnea: an American Academy of Sleep Medicine Clinical Practice Guideline. J Clin Sleep Med 2017;13:479-504.

23. Frey WC, Pilcher J. Obstructive sleep-related breathing disorders in patients evaluated for bariatric surgery. Obes Surg 2003; 13:676-83.

24. O'Keeffe T, Patterson EJ. Evidence supporting routine polysomnography before bariatric surgery. Obes Surg 2004;14: 23-6.

25. Musman S, Passos VM, Silva IB, Barreto SM. Evaluation of a prediction model for sleep apnea in patients submitted to polysomnography. J Bras Pneumol 2011;37:75-84.

26. Chung F, Abdullah HR, Liao P. STOP-Bang Questionnaire: a practical approach to screen for obstructive sleep apnea. Chest 2016;149:631-8.

27. Peppard PE, Young T, Barnet JH, Palta M, Hagen EW, Hla $\mathrm{KM}$. Increased prevalence of sleep-disordered breathing in adults. Am J Epidemiol 2013;177:1006-14.

28. Ashwell M, Gunn P, Gibson S. Waist-to-height ratio is a better screening tool than waist circumference and BMI for adult cardiometabolic risk factors: systematic review and meta-analysis. Obes Rev 2012;13:275-86.

29. Jayawardana $R$, Ranasinghe $P$, Sheriff $M H$, Matthews $D R$, Katulanda P. Waist to height ratio: a better anthropometric marker of diabetes and cardio-metabolic risks in South Asian adults. Diabetes Res Clin Pract 2013;99:292-9.

30. Ahbab S, Ataoglu HE, Tuna M, Karasulu L, Cetin F, Temiz LU, et al. Neck circumference, metabolic syndrome and obstructive sleep apnea syndrome; evaluation of possible linkage. Med Sci Monit 2013;19:111-7.

31. Borel AL, Coumes S, Reche F, Ruckly S, Pépin JL, Tamisier $\mathrm{R}$, et al. Waist, neck circumferences, waist-to-hip ratio: Which is the best cardiometabolic risk marker in women with severe obesity? The SOON cohort. Plos One 2018;13: e0206617.

32. International Diabetes Institute, World Health Organization. The Asia-Pacific perspective: redefining obesity and its treatment. Melbourne: Health Communications Australia; 2000. 